Original Research Paper

\title{
Body Consciousness and Self-Objectification in Gen Z Adolescent Girls
}

\author{
Tarika Sandhu and Sargun Sandhu
}

Department of Psychology, Punjabi University Patiala, India

\author{
Article history \\ Received: $12-12-2020$ \\ Revised: 25-02-2021 \\ Accepted: 01-03-2021 \\ Corresponding Author: \\ Tarika Sandhu \\ Department of Psychology, \\ Punjabi University Patiala, \\ India \\ Email: tarika@pbi.ac.in
}

\begin{abstract}
In contemporary Indian society media has magnified age-old pressures for teenage girls to conform to stereotypical standards. Contemporary Indian mythologist and author, Devdutt Pattanaik gives us a vivid picture of the socio-cultural and religious genesis of the Indian society. He validates the inherent gender-based inequality so characteristic of the Indian society in his book, 7 Secrets of the Goddess "A woman stops being a person; she is dehumanized and turned into a symbol of masculine honor, this transformation from prized possession to venerated object marks the triumph of patriarchy". This objectification of the female body not only instigates shame and dread but also encourages chasing what society thinks is ideal. The present study thus aimed to explore the role of self-objectification in objectified body consciousness i.e., body surveillance, body shame and appearance control beliefs of adolescent females age ranging (15 to 19$)$ from Punjab ( $n=60)$. Self-Objectification Scale was used to screen in females high and low on self-objectification. Alongside scores on the subscales of Objectified Body Consciousness Scale (OBCS) were obtained. The findings suggested that media images have a detrimental effect on adolescent psyche. It's imperative to improve a woman's experience of her own body. Psycho-educational interventions in school and colleges should be introduced which focus on presenting and reinforcing a critical stance toward female beauty standards, in order to prevent-or at least reducehigh levels of internalization and social comparison.
\end{abstract}

Keywords: Self-Objectification, Objectified Body Consciousness, Adolescent Females

\section{Introduction}

Contemporary times have heralded an objectified perspective in the understanding of a woman. Selfobjectification, is a particular view of self that can lead to a form of self-consciousness characterized by the habitual monitoring of the body's outward appearance. Objectification of the female body prevails along a continuum ranging from the literal (e.g., human sex trafficking, modelling, participating in pageants) to figurative (e.g., media representations, using women's bodies in advertising etc.). Objectification can be experienced both directly (e.g., women and girls' personal experiences of being judged on their appearance and sexual desirability) as well as indirectly (i.e., women and girls' reflection of the treatment and objectification of other women and girls) (Crawford et al., 2009). This objectification has evolved as a manifestation of consumerist and patriarchal mindsets both at cultural as well as interpersonal levels. The consumerist trend finds it convenient to primarily value women for their appearance since males have long been enticed by tapping on the basal instincts. On the other hand, a patriarchal society as an organized structure of interpersonal relationships within groups or clusters of people subliminally and out rightly introjects within the female psyche that she needs to be protected and is not equal to the male counterpart. Unknowingly women too have internalized these externally derived standards of valuing themselves and are thus caught in proving themselves to others rather than becoming inner oriented to their genuine character. These feelings have unfortunately passed down to Generation $\mathrm{Z}$ females as well who are caught in the same whirlpool of self-doubt, self-scrutiny, shame etc. Generation Z (or simply Gen Z), popularly known as Zoomers, is the demographic unit succeeding Millennials and preceding Generation Alpha. Researchers and popular media draw the mid-to-late 1990s as starting 
birth years and the early 2010s as ending birth years. Having grown up as a social generation with open gateway to the Internet and portable digital technology from a young age, members of Generation $\mathrm{Z}$ have thus been named "digital natives". Although being born in this digital era helps the zoomers to have an easy access to everything it also has potential negative effects like early onset of puberty, mental health problems, decreased performance in academics, sleep disorders etc. (Hochberg and Konner, 2020; APA, 2007; Schraer, 2019; Twenge, 2017) one such issue is the rapid rise of media induced self-objectification in females especially adolescents. Objectification theory (Fredrickson and Roberts, 1997) presents a base to interpret a variety of psychological and physical consequences women may encounter as a result of living in a culture that objectifies their physique. This theory illustrates the process through which women internalize the belief that appearance is an indispensable component of their worth. It talks about how cultural stereotypes of physical appearance leads to an overarching effect of the individual being evaluated based on these norms.

Objectification theory (Fredrickson and Roberts, 1997) harnessed feminist principles in order to explain women's experiences of sexualization and its negative consequences on women's health and wellness. Theorists posit that from an early age on, women's bodies are looked at, commented on and judged by others. Living through and observing sexual objectification, girls and women learn that (sexual) attractiveness is a key aspect of the feminine gender role and therefore a goal for which they must aspire (Fredrickson and Roberts, 1997). Objectification theory has unceasingly been magnified to include more diverse populations, including men, sexual minorities and ethnic minorities (Fredrickson et al., 2011).

Objectification theory (Fredrickson and Roberts, 1997) does not attempt to address 'why' sexual objectification is rampantly infiltrating our culture. Instead, the theory examines how living in a socialcultural context that sexualizes and dehumanizes the female body can lead to specific negative affective experiences and mental health risks for women and girls. When these unrealistic standards are connected by women to their identity and self-worth, they most commonly experience the feelings of shame and anxiety about their bodies (Bartky, 1988; Lewis, 2008). Noll and Fredrickson (1998) posited objectification to be associated with a collection of emotional and physical corollaries like an increase in body shame, body dissatisfaction, decreased awareness of internal states, depression, sexual dysfunction and indications of eating disorder pathology.
In a similar tone (Herman, 1994; Ussher, 1989) have discussed that living in a society where sexual objectification is ubiquitous, a conceivable result of this will be that girls and women will internalize these experiences and begin to objectify their own selves. That is, over time women discover, through both their interpersonal encounters and vicarious observation of society and popular culture, that their "looks" matter, that other people's view of their outward selves can determine their worth and, these assessments can even affect the quality of their social and economic lives. Females learn society's emphasis on attractiveness early in life. Developmental studies depict that girls are more concerned than boys about having an attractive appearance (Douvan et al., 1966). The media message, continuously endorsing women's need to be attractive, clearly influences children and adults alike. Given this persistent indoctrination into sociocultural attitudes toward female appearance, it is not surprising that females begin to internalize these early standards. This all-in turn leads to females developing a poor self-concept where they measure their current self with the ideal all throughout their lives and experience feelings of body dissatisfaction when these ideals aren't met. The pervasiveness of the perception of women as primarily creatures of physical attributes has become so normalised in our lives that it has birthed a new concept of 'normative discontent'. The term suggests that as a society we have started considering it normal for girls and women to be dissatisfied with their bodies and the same is portrayed and fixated through media platforms.

McKinley and Hyde's (1996) construct of objectified body consciousness theoretically appears to be an outcome of self-objectification. It entails three primary components: Self-surveillance, body shame and appearance control. An individual with an objectified body consciousness scrutinizes his/her body from a third person view point, exhibits body shame when they fail to achieve the cultural expectancies and believes that individuals are able to control their appearance, respectively. Objectified body consciousness thus, can be seen as an outcome of pervasive self-objectification.

\section{Objectified Body Consciousness}

McKinley and Hyde's (1996) proposed that the outcome of objectification would be the starting point to Objectified Body Consciousness (OBC). Greater levels of $\mathrm{OBC}$ have been documented to lead to negative body experience for women. OBC consists of three elements that feminist theorists (Bartky, 1988; Spitzack, 1990) claim to have played a crucial role in 
women's body experience via (a) body surveillance, (b) internalization of cultural body standards and (c) beliefs about appearance control.

\section{Body Surveillance}

The focal percept of OBC is that the feminine body is fashioned as an object of male desire and so remains to receive the gaze of the male "other" (Spitzack, 1990). Constant self-surveillance, witnessing their selves from the eyes of others, is required to ensure that women abide by the cultural body standards and dodge negative judgments. Persistent societal pressure, results in women learning to equate body surveillance to self-love, health and individual achievement (Spitzack, 1990). Continual self-surveillance impacts women negatively. Psychological research has shown that when the focus of our attention is upon self and we are aware of society's perceived ideal norms, we compare ourselves to that standard and try to reduce any discrepancy. If we cannot reduce the inconsistency, we feel bad (Carver and Scheier, 1981). Experimental data also indicates that focussing on self can make us vulnerable to be influenced by other people and reduces our capacity to focus on the outside world (Carver and Scheier, 1981).

Self-objectification accompanied by marked body surveillance is reported to promote body shame and anxiety and reduce or disrupt awareness of internal bodily states and flow experiences (Fredrickson and Roberts, 1997). Drawing parallels to internalized cultural standards and perceiving oneself as failing to meet them leads to the emergence of body shame. There is also a fall in peak motivational states, which (Csikszentmihalyi and Csikzentmihaly, 1990) termed as flow, are "rare moments during which we feel we are truly living, uncontrolled by others, creative and joyful" (Fredrickson and Roberts, 1997).

Body surveillance thus, functions as a way to monitor progress toward or ensure submission to the ideal body (e.g., Calogero and Thompson, 2010; Knauss et al., 2008). Body surveillance is likely to result into body shame when individuals recognize the incongruity between their actual and ideal physical selves (e.g., Calogero and Thompson, 2010; Fitzsimmons-Craft et al., 2011; Moradi, 2010; Slater and Tiggemann, 2010; Tiggemann, 2013).

\section{Body Shame}

Internalization of cultural body standards can result to intense shame (Bartky, 1988). Societal messages about beauty (i.e., what it is, how it should be cultivated and how it will be rewarded) permeate our minds through extensive media representation. (Rubin et al., 2004). Cultural body standards specify the ideal to which a woman parallels herself when she examines her body. Women themselves want to be "beautiful." When this desire becomes a personal choice, women comply more than when they believe the standards were externally enforced (Spitzack, 1990). However, there is immense economic and interpersonal pressure on women to be a certain body type (Bartky, 1988; Rodin et al., 1984). Women who compare themselves to images in the media carry false beliefs of being bulkier than they actually are. Idealised media images are routinely subjected to manipulation and massive editing, such as photoshopping (e.g., face filters, body alterations etc.). The resulting images present an unobtainable 'aesthetic perfection' that is unattainable in reality (Paraskeva et al., 2017).

Body dissatisfaction gives rise to negative attitudes and habits, lowers self-esteem and leads to feelings of self-doubt in young women. Preoccupations with possessing an ideal shape could be psychologically detrimental to young women, who may then resort to excessive grooming and dieting along with a desire to undergo surgery (Cash and Linda, 2011). Because cultural standards for the feminine body are unrealistic and unachievable, women who internalize them, connecting achievement of those standards with their identity, may fall victims to shame of not being able to achieve them (Rodin et al., 1984). This shame is not just negative orientation towards the body but also the self. Bartky (1988) explained that the amount of shame a woman experiences towards her body is a direct measure of the extent of internalization of cultural standards by her.

\section{Appearance Control Beliefs}

OBC theory assumes that women are responsible for how their bodies look and can control their appearance and comply with cultural standards by directing efforts in this direction. Creating a belief in women that they hold the power to how they look is crucial to make them accept attractiveness as a reasonable standard by which to judge themselves (Wolf, 1991). When achievement of cultural body standards is presented as a choice it fortifies the belief that appearance can be controlled. Even though appearance to a large extent is uncontrollable, the belief itself that it can be controlled is beneficial to women. Engaging in activities directed towards controlling appearance provides women with a gateway to resolve the discrepancy between being "feminine" and being instrumental (Rodin et al., 1984).

Belief in being able to control their appearance instils in women a sense of accomplishment that they do not easily give up (Bartky, 1988). The perceived state of control is said to improve the psychological and physical wellbeing of the individual (Cromwell et al., 1977; Taylor, 1989). This finding thus holds great value because cultural standards for body appearance are difficult and impossible for many to achieve. This perceived control helps to cope with stressful situations and motivates a woman towards goal achievement (Taylor, 1989). 
Unfortunately, control beliefs can also lead to negative outcomes such as eating disorder pathology. Restricted eating is detrimental to health, can actually induce weight gain by changing metabolic processes and is the most underestimated cause of illness in Western society (Ernsberger and Haskew, 1987). The unavoidable weight gain post food restriction possesses an increased risk of diabetes, high blood pressure and heart disease (Ernsberger and Haskew, 1987). Appearance control beliefs can also further trigger body surveillance and simultaneously galvanize self-blame for perceived lack of control-this interaction can also lead to major eating disorders (Dakanalis et al., 2015; McKinley and Hyde, 1996; Sinclair, 2010).

\section{Review of Literature}

\section{Self-Objectification and Objectified Body Consciousness in Adolescence}

Adolescence is an important period to understand the development of self-objectification and analyze its consequences. Fredrickson and Roberts (1997) originally put forth the argument that the onset of puberty, is the time when girls' bodies begin to mature and change and become the focus of attention and scrutiny by others. Physical changes are accompanied by adolescents' increase in self-awareness and preoccupation with image (Harter and Leahy, 1999), thus, this age becomes a critical period for the development of self-objectification.

There exist considerable differences in the individual timing and tempo of puberty (Tanner, 1971). Research in areas of body image and body dissatisfaction have repeatedly revealed a variety of psychosocial problems in adolescence, including depression and eating disorders (Angold et al., 1998; Weichold et al., 2003). Body image and body dissatisfaction studies suggest that body shame may develop as a result of pubertal changes. The onset of puberty ignites striking changes in the physical demeanor. For example, normal female pubertal development involves the addition of approximately 24 pounds of body fat (Warren, 1983) which depicts a typical change in body fat composition from about 16 to $27 \%$ and a muscle-to-fat ratio of 5 to 4 by the conclusion of puberty (Smith et al., 1990). Changes in the physical body and the male attention that these changes attract lead them to feel more aware and conscious to these bodily changes in turn making them more vulnerable to objectification.

The American Psychological Association Task Force on the Sexualization of Girls' 2007 report on the sexualization of girls highlighted the need for research on the effects of self-objectification in girls, although initially there was scarcity in research in the area but there has been an increase in the number of studies recently (Hyde et al., 2006; Strauss et al., 2015; Karsay et al., 2018; Daniels et al., 2020).

Noser and Hill (2014) examined whether objectified body consciousness mediates the association between appearance contingent self-worth and low levels of appearance self-esteem in a sample of 465 female undergraduates. They sought to use a multiple mediation model to examine whether components of objectified body consciousness (i.e., body surveillance, body shame and control beliefs) play unique roles in the connection between appearance contingent self-worth and appearance self-esteem. Results showed that body surveillance and body shame were significant mediators of the connection between appearance contingent selfworth and low levels of appearance self-esteem.

Lindberg et al. (2006), in a study conducted on 166 girls between 10-to 12-years-old (mean age 11.2 years) exhibited that more radical pubertal growth and greater sexual harassment from peers predicts increases in both girls' engagement in self-surveillance as well as body shame. A large body researches have supported that body image concerns and dissatisfaction are prevalent in most adolescent girls, both clinical and non-clinical samples (Smolak and Levine, 2001; Thompson et al., 1999), regardless of eating pathology or weight (Rodin et al., 1984); findings have subsequently been explained as "normative discontent. To sum up, the bodily changes and resulting experiences that occur for girls throughout the transition to adolescence may trigger the development of self-surveillance.

With the current social ideal for prepubertal females being super skinny and Barbie doll type models, the weight gain and bodily changes that begin at this level are also a likely source of adolescent girls' dissatisfaction with their bodies (Spitzer et al., 1999; Stice and Whitenton, 2002). These sudden body changes may deviate or enhance adolescents' vulnerability toward self-consciousness (Rankin et al., 2004). Studies in the past have documented that directing individuals' attention to their physical appearance, even temporarily, can result in increased reports of self-surveillance as well as body shame (e.g., Fredrickson et al., 1997; Martins et al., 2007). Puberty leads to an increase in attention focused towards own physical appearance and is likely to draw others' attention to the adolescent's body; attention that is commonly in the form of peer sexual vexation, particularly for early developing girls (AAUW, 2001).

Tylka and Sabik (2010) delved into Social Comparison Theory (Festinger, 1954) and self-esteem as they were integrated into the framework of Objectification Theory (Fredrickson and Roberts, 1997). Their study involved two hundred and seventy-four women from a Midwestern U.S. college who were asked to fill in the Feedback on Physical Appearance Scale 
(Tantleff-Dunn et al., 1995), the Rosenberg Self Esteem Scale (Rosenberg, 1965), the Body Surveillance subscale and the Body Shame subscale of the Objectified Body Consciousness Scale (McKinley and Hyde, 1996), the Body Comparison Scale (Fisher et al., 1998) and the Eating Attitudes Test-26 (Garner et al., 1982). The results indicated that being absorbed in their own bodies makes women, more attentive to the appearance of other women's bodies and how they compare that to their own. This body comparison may act as a feedback loop to their own body, extending heightened body surveillance and objectification of other women's bodies. The researchers also found that self-esteem to be a significant predictor of body surveillance, body comparison and body shame.

A study with Caucasian 10-to12-year-old girls showed that pubertal development positively correlated with selfsurveillance among girls but not boys (Lindberg et al., 2006). Moreover, pubertal growth was indirectly associated with self-surveillance through sexual objectification. With advanced pubertal changes, girls experienced greater vulnerability to sexual harassment from peers. The more pronounced experience of sexual harassment greater was their level of self-surveillance (Lindberg et al., 2006).

\section{Media and Body Consciousness}

Butkowski et al. (2019) made use of objectification theory to explore how value placed on selfie feedback among young women relates to markers of body image disturbance, including body dissatisfaction, drive for thinness and bulimia action tendencies. They found that women who invested deeply in selfie feedback expressed more body dissatisfaction and drive for thinness through the indirect influence of body surveillance, but this effect did not extend to bulimic tendencies. As per the findings when young adult female Instagram users gave greater importance to audience responses to their selfies, they were more likely to exhibit disordered eating attitudes and intentions.

Boursier et al. (2020) aimed to evaluate the unexplored predictive role of appearance control beliefs on problematic SNS (Social Networking sites) use, testing the mediating effect of Body Image Control in Photos (BICP) across male and female groups. The study involved 693 adolescents (55\% females; mean age 16 years). Results showed that appearance control beliefs are a strong negative predictor for control over body image in photos. BICP also further, mediated the appearance control beliefs' negative impact on problematic SNS use in girls.

Frison and Eggermont (2016) studied the effect of negative comparison on Facebook and body image dissatisfaction among 1840 Belgian female adolescents whose ages ranged from 12-19 years $(\mathrm{M}=14.76, \mathrm{SD}=$ $1.41)$ and were sampled in an online survey. The negative comparison on Facebook scale and the body shape satisfaction scale all developed by the researchers were employed to elicit data from the participants. Findings revealed that negative comments about body shape on Facebook resulted in the removal of such pictures. They were replaced by photographs which the female account holder and her friends found to be more conforming to the social media community's likings. The study concluded that girls prefer using slim shaped images of either themselves or their role models as Facebook profile pictures than fat shaped pictures and that fat females will embark on exercises and dieting to reduce their shape when they are told by their social media friends that they are gaining more weight than the expected ideal.

Amazue (2014) studied the influence of the media and body image concerns to female adolescents' self-esteem in Nigerian 200 secondary school female adolescent from the urban and rural contexts were involved in the study and their ages ranged from 12-17 years $(\mathrm{M}=13.5)$ The result showed that social media correlated significantly and positively with body image concerns among the respondents. This suggested that the female adolescents who use the social media (Facebook, Whats App, 2g0) frequently are more concerned about their body image than those who do not use social media platforms.

In another study, (Fardouly et al., 2015) explored the effect of Facebook picture shapes on women's body image and appearance. One hundred and twelve females aged 12$17(\mathrm{M}=14.3, \mathrm{SD}=2.8)$ were randomly assigned to Facebook and non-Facebook groups. The study result indicated that female adolescents who spend time on Facebook reported more negative feeling concerning their body image (size and weight) after seeing the pictures and images or shapes of other such as those regarded as role models and celebrities. It was also stated that spending time on Facebook led to greater desire to change their facial appearance, hair and skin related features, while those who do not use the social media constantly or at all show little or no concern about their shape and how they differ from that of established celebrities. Thus, it was established that social media has a significant effect on young females' perception and reaction to their body shape/size and weight.

Kim and Chock (2015) investigated the association between adolescent's social media use and body image attitudes and the drive for thinness and muscularity among 119 females and 67 males whose age range is 16-25 years $(\mathrm{M}=19.75, \mathrm{SD}=2.06)$. Results revealed that there was no correlation between body image concerns and time spent on social media. However, viewing and commenting on peer's profiles had significant association with drive for thinness for females and muscularity for males. The study concluded that social media use was a significant predictor of body image acceptance and action.

As major part of the previous research was carried out in western societies, we therefore in the current study 
attempted to explore the relationship between these variables in Indian population.

\section{Rationale of the Study}

India is emerging as one of the fastest growing economies and boasts of having the largest youngest population Census of India, 2011. Most of this population is involved in activities that bring forth an identity transformation. Observed that globalization of Indian economy has put a pressure on young Indian women to meet the standards of international beauty.

Feminine self-worth develops and expands under the influence of a wide spectrum of factors such as familial reinforcing patterns, societal expectations, cultural stereotypes and flashing media trends etc. These norms get interjected in to the impressionable young woman's selfconstrual system. Distortions begin to occur in the understanding of one's own self since it has not matured enough to impose regulatory checks on impressions being casted from external sources. Thus, it is assumed that self- objectification silently corrodes the female adolescent's self-construal, leading to heightened objectified body consciousness.

The present study aimed to investigate the role of SelfObjectification on the components of objectified body consciousness i.e., body surveillance, body shame and appearance control beliefs in adolescent females between the ages of 15 and 19 years. The influence of Self-Objectification and OBCS has been well documented in women in the western milieu (Grabe et al., 2007; Parent and Moradi, 2015; Tolaymat and Moradi, 2011; Velez et al., 2015) but there is dearth of research in the adolescent females from the Indian sub-continent.

\section{Method}

\section{Participants}

Technique of incidental sampling was used for the purpose of data collection. The initial sample included 183 adolescent females, i.e., 10th-12th grade students of private schools and female college freshmen from public colleges of Patiala, State of Punjab, India. The age range of the sample was 15-19 years with mean age (17 years, 2 months). During the initial screening phase, the participants were administered The Self-Objectification Scale (Noll and Fredrickson, 1998). According to the scoring criteria laid down in the manual of the SelfObjectification Scale, adolescent females scoring high on self- objectification $(n=60)$ were grouped in the high self-objectification category. Similarly, the adolescent females scoring low $(n=60)$ were grouped in the low self-objectification category. They were then administered the Objectified Body Consciousness Scale (OBCS; McKinley and Hyde, 1996) and their scores were tabulated for analyses.

\section{Measures of Assessment}

\author{
Self-Objectification Questionnaire by Noll and \\ Fredrickson (1998)
}

The Self-Objectification Questionnaire (Noll and Fredrickson, 1998) comprises of ten rank-ordered items. Each item identifies a different body aspect and participants rank them from 0 (least important) to 9 (most important) with respect to their perception of their own looks and body. Five of the items are competencebased (strength, physical coordination, energy level, health and physical fitness) and five are appearance-based (weight, sex appeal, physical attractiveness, firm/sculpted muscles and body measurements). Scores may range from -25 to 25 , with higher scores indicating higher levels of self-objectification.

Reliability of the scale is determined by correlating the sum of the appearance ranks and the sum of the competence ranks (Hill and Fischer, 2008). A strong negative correlation was reported between appearance and competence rankings, indicating good reliability ( $\mathrm{r}=$ -0.88) in the study conducted by (Calogero and Jost, 2011). A similar study by (Hill and Fischer, 2008) also found good reliability $(\mathrm{r}=-0.81)$.

\section{Objectified Body Consciousness Scale by McKinley and Hyde (1996)}

This scale is a self-report measure of body consciousness consisting of 24 items. The OBCS contains three subscales; (a) Body Surveillance-A measure of defining the body by how it looks, as opposed to how it feels. (b) Body Shame-A measure of whether someone believes they are a bad person because they do not meet the cultural standard for what a body should look like. (c) Appearance Control Beliefs-A measure of whether or not a person believes they can control their own appearance, or if it is controlled by other things. Internal consistency for the OBCS $=($ Cronbach's $\alpha=0.75)$

\section{Hypotheses}

- H1: Females high on Self-Objectification would have higher scores on Body Surveillance and Body Shame components of OBCS as compared to those low on Self-Objectification

- H2: There will be no significant difference on Appearance Control Beliefs in females high and low on Self-Objectification

\section{Procedure}

The data was collected from 10th-12th grade female adolescent students of private schools and college freshmen (females) from public colleges of Patiala, state 
of Punjab, India. Prior to data collection, due consent of school authorities and parents was obtained. Disclosure of the study's intent was done with the participants involved in the study. The initial session focused on rapport building. Ethical considerations of the study were clearly explained during this session and they were assured of confidentiality of test results. The participants filled in the Self-Objectification Scale (Noll and Fredrickson, 1998) which was used to screen in females high and low on selfobjectification. Additionally, the scale of Objectified Body Consciousness Scale (OBCS; McKinley and Hyde, 1996) was administered.

\section{Results and Discussion}

The main objective of the study was to explore the role of Self-Objectification in Objectified body consciousness indices namely- Body Surveillance, Body Shame and Appearance Control Beliefs in adolescent females between the ages of 15 and 19. Analysis of results provided empirical evidence that psychological dysfunction results from an adolescent female's preoccupation with her bodily appearance (McKinley, 2006; Lindberg et al., 2006; Schooler et al., 2006; Tolman et al., 2006):

- According to Tables 1 and 2 i.e., Mean and the OneWay ANOVA summary table, females high on selfobjectification had significantly higher scores $(\mathrm{M}=$ 31.13) on Body Surveillance index of OBCS in comparison to low self-objectification group $(\mathrm{M}=27.2)$ which was significant at 0.05 levels $[\mathrm{F}$ $(1,59)=5.72, \quad \mathrm{p}<0.05)]$. This leads to the conclusion that adolescent females in high selfobjectification group were significantly higher on Body Surveillance index of OBCS as compared to the low self-objectification group. These findings depict that females high on self-objectification are high on monitoring their body in response to the outside gaze and societal expectations

This leads to a form of self-consciousness characterized by continuous monitoring of the body's outer appearance. This chronic body monitoring is referred to as self-surveillance (also referred to as body surveillance) represents the behavioral manifestation of self-objectification. Objectification theory further states that surveillance usually leads to body dissatisfaction because it increases self-focused attention and concerns regarding negative evaluations by others. In similar vein Tylka (2004) in his study observed a correlation of -0.48 between surveillance and body satisfaction in 373 college women and in a study by (Forbes et al., 2006) a correlation of -0.48 was seen between surveillance and weight satisfaction in 123 college women.
The finding stands true in a patriarchal society which is most common in our country wherein women have been assumed with certainly less powers than men. The female sex has been portrayed as being gentle, submissive and passive to the dominant male sex, where the latter has been rendered as independent, callous and impulsive. The women in general are reduced to just taking care of the household and bearing children. Even if somewhere, they are acknowledged as part of the working class, it has to be the occupation which has a touch of tender care like teachers or nurses.

Thus, objectification not only instigates anxiety but also encourages the build-up of shame. Since the adolescent female perceives herself as not matching up to media standards, she continues to chase the ideal image. This is a futile search since external standards are continually changing and are uncontrollable. As a result of which the adolescent female, experiences an incessant need to keep monitoring her physical appearance through body surveillance. The psychological implications of body surveillance range from lowered self-esteem, depression, feeling of discontent with self and other psychological disorders (Amazue, 2014; Noser and Hill, 2014; Tylka and Sabik, 2010).

In the Indian context, (Dixit et al., 2011) explored body consciousness in adolescent females. Results illustrated that about $20.5 \%$ of participants showed aspiration to become thin. $73.4 \%$ adolescent girls were comfortable with their bodies, while $26.6 \%$ were dissatisfied. The dissatisfaction was higher among girls of urban $(30.2 \%)$ and slum $(40.0 \%)$ areas in comparison to rural $(22.5 \%)$ area. Girls aged 13-15 years were less satisfied with their bodies $(69.9 \%)$ in comparison to 10 12 years $(76.5 \%)$ and $16-19$ years $(76.4 \%)$. Girls who reported to be satisfied with their body image, girls were found underweight (32.8\%) and were stunted (38.45\%).

Tables 1 and 3 shows the mean and ANOVA summary table, females high on self-objectification had significantly higher scores $(\mathrm{M}=32.67)$ on Body Shame index of OBCS in comparison to low self-objectification group $(\mathrm{M}=23.4)$ and it was significant at 0.01 level $[\mathrm{F}$ $(1,59)=20.05, \mathrm{p}<0.01)]$. These results indicate that females high on self-objectification are more conscious of their looks and set unrealistically high standards for themselves in an effort to meet the external beauty standards. Thus, the first hypothesis stating that "Females high on Self-Objectification would have significantly higher scores on Body Surveillance and Body Shame components of OBCS as compared to those low on SelfObjectification" stands validated.

Adolescent females get caught in a vicious cycle of trying to achieve unrealistic standards and experiencing failure related to it. Research also indicates that heightened self-objectification further 
gives rise to feelings of body shame, general shame and body-related thoughts (Fredrickson et al., 1997; Quinn et al., 2006). Muehlenkamp and Saris-Baglama (2002) stated that when young girls realise the importance of a woman's appearance in a patriarchal culture it contributes to feelings of fear, shame and disgust that some of them experience during the transition from girlhood to womanhood.

Further, self-objectification and body shame show linkages to restrained eating.There isalso considerable evidence supporting the core mediational model proposed by objectification theory, wherein body shame mediates the association between self-objectification and eating pathology (Calogero, 2009; Dakanalis et al., 2015; Fredrickson et al., 1997; Tiggemann and Williams, 2012; Tylka and Hill, 2004).

To summarize the above findings, internalization of beauty ideals are a strong predecessor of selfobjectification and consequently body surveillance and body shame. Over the years several studies have documented girls' and women's reporting experiences of pressures to be thin, which are a specific manifestation of sexual objectification experiences. Data from studies so far indicates that reported experiences of weight-related criticism, thinness pressures and sexual and appearance-related harassment show positive associations with body surveillance and body shame in samples of predominantly white college women and young girls (Lindberg et al., 2006; Lindberg et al., 2006; Tylka and Hill, 2004).

Referring to Tables 1 and 4 we can see that mean values of Appearance Control Beliefs for females high on self-objectification $(M=39.7)$ and for females in low self- objectification group ( $M=35.43)$ which was significant at 0.05 levels $[\mathrm{F}(1,59)=6.91, \mathrm{p}<0.05)]$. This indicates that heightened self-objectification leads to an increase in feelings of controlling one's own appearance to meet a perceived external criterion. This is contrary to the second hypothesis which stated that "There will be no significant difference between females high and low on selfobjectification on Appearance Control Beliefs Index". Conventionally, appearance control beliefs have been documented as a controversial and much debated factor of OBC. McKinley and Hyde (1996) in their OBC theory placed appearance control beliefs in a dubious position in relation to self-objectification (John and Ebbeck, 2008). Even though they hypothesized that higher appearance control beliefs might contribute to an individual's experiencing their body negatively, subsequent studies have reported a negative intercorrelation or no association between the indices of OBCs i.e., body surveillance, body shame, appearance control beliefs and other body-related negative outcomes (i.e., eating disorder symptomatology and internalization of cultural standards of attractiveness) (McKinley and Hyde, 1996; Sinclair and Myers, 2004; Moradi, 2010; Sinclair, 2010; Fitzsimmons-Craft et al., 2011). However, in the current study self-objectification levels appear to effect appearance control beliefs. One possibility for present findings can be interpreted with regard to the cultural context. The sample of previous studies (Grabe et al., 2007; Parent and Moradi, 2015; Tolaymat and Moradi 2011; Velez et al., 2015) primarily constituted of white women whereas the present study was conducted on NorthIndian adolescent girls. Young girls in India are seen through the prism of strong patriarchal influences (Paraskeva et al., 2017; Loughnan et al., 2015; Dixit et al., 2011).

Table1: Means, SD's and F values of female zoomers high and low on Self-Objectification on components of Objectified Body Consciousness $(\mathrm{N}=60)$

\begin{tabular}{llllll}
\hline & High on Self-Objectification $(\mathrm{N}=60)$ & \multicolumn{2}{l}{ Low on Self-Objectification $(\mathrm{N}=60)$} & \\
& - & $\mathrm{SD}$ & Mean & SD & F(ANOVA) \\
\hline Variables & Mean & 7.04 & 27.20 & 5.63 & $5.72^{*}$ \\
Body surveillance & 31.13 & 8.02 & 23.40 & 8.01 & $20.05^{* *}$ \\
Body shame & 32.67 & 7.63 & 35.43 & 4.56 & $6.91 *$ \\
Appearance control & 39.70 & &
\end{tabular}

$* \mathrm{p}<0.5$

$* * \mathrm{p}<0.01$

Table 2: Showing ANOVA scores for Body Surveillance in adolescent girls high and low on Self objectification $(\mathrm{N}=60)$

\begin{tabular}{|c|c|c|c|c|c|}
\hline Variable & $\begin{array}{l}\text { Source of } \\
\text { variation }\end{array}$ & $\begin{array}{l}\text { Sum of } \\
\text { squares }\end{array}$ & df & $\begin{array}{l}\text { Mean } \\
\text { squares }\end{array}$ & $\begin{array}{l}\text { F } \\
\text { (ANOVA) }\end{array}$ \\
\hline Body & Between groups & 232.067 & 1.000 & 232.067 & $5.72 *$ \\
\hline Surveillance & Within groups & & 2354.267 & 58.000 & 40.591 \\
\hline & Total & & 2586.333 & 59.000 & \\
\hline
\end{tabular}

\footnotetext{
$* * \mathrm{p}<0.01$
}

$* \mathrm{p}<0.05$ 
Table 3: Showing ANOVA scores for Body Shame in adolescent girls high and low on Self objectification

\begin{tabular}{llllll}
\hline Variable & Source of variation & Sum of squares & df & Mean squares & F (ANOVA) \\
\hline Body shame & Between groups & 1288.067 & 10 & 1288.067 & $20.05^{* *}$ \\
& Within groups & 3725.867 & 58 & 64.239 & \\
& Total & 5013.933 & 59 & & \\
\hline
\end{tabular}

$* * \mathrm{p}<0.01$

$* \mathrm{p}<0.05$

Table 4: Showing ANOVA scores for Appearance Control Beliefs in adolescent girls high and low on Self objectification

\begin{tabular}{llllll}
\hline Variable & $\begin{array}{l}\text { Source of } \\
\text { variation }\end{array}$ & $\begin{array}{l}\text { Sum of } \\
\text { squares }\end{array}$ & df & $\begin{array}{l}\text { Mean } \\
\text { squares }\end{array}$ & $\begin{array}{l}\text { F } \\
\text { (ANOVA) }\end{array}$ \\
\hline $\begin{array}{l}\text { Appearance } \\
\text { Control }\end{array}$ & Between groups & 273.067 & 1.000 & 273.067 & $6.91^{*}$ \\
Beliefs & Within Groups & 273.067 & 2293.667 & 58.000 & 39.546 \\
Total & 2566.733 & 59.000 & & & \\
\hline
\end{tabular}

$* * \mathrm{p}<0.01$

$* \mathrm{p}<0.05$

\section{Limitations of the Study}

A major limitation of the study was the sample size. Generalizability of results thus restricted. The psychological assessment tools did not incorporate a lie scale or any such measure to check social desirability. Additional use of qualitative measures can be used to supplement the existing knowledge framework with regard to self-objectification in adolescent females.

\section{Implications and Future Directions}

There is a pressing need to acknowledge the presence of the silent psychological epidemic of self-objectification affecting the young and vulnerable generation. Subsequently psychological theory building and interventions should cater to the growing menace of body preoccupation. Given the fact that objectification experiences account for variance in both body surveillance and body shame, researchers should consider integrating feminist and social constructionist approaches to understanding of the development of negative body experience in adolescent females.

Future research needs to replicate and extend the study to samples that include more diverse populations. One such group could be pre-adolescent females entering puberty. Longitudinal studies could help determine the exact role of various sociocultural factors in the development of objectification experiences over time. In addition, qualitative research focusing on the lived experience of objectification experiences may provide a better understanding of its onset and spread. Psycho-educational interventions should challenge mindsets blindly following unrealistic beauty standards and simultaneously strengthen attitudes that value diversity in the human form.

\section{Acknowledgment}

Funding for the study and paper publication was received from the Indian Council of Social Science Research (ICSSR) as part of the Major Research Project under the "IMPRESS Scheme (2019-2021) titled, "Media induced Self-Objectification in adolescent females: efficacy of Johari window based intervention".

\section{Author's Contributions}

Dr. Tarika Sandhu: Designed and organised the study, provided intellectual framework for drafting of the article, reviewed it critically for content and supervised data analysis.

Ms. Sargun Sandhu: Contributed in data collection, data analysis and drafting the manuscript.

\section{Ethics}

Ethical considerations were given primary importance during the conductance of the study. Prior to data collection, informed consent of school authorities, students and their parents were obtained. Disclosure of the study's intent was done after data collection so that no faking of responses took place due to prior knowledge about the aims of the study. Confidentiality of test results was strictly maintained.

\section{References}

Amazue, L. O. (2014). The contributions of media, body image concerns and locality to the perceived selfesteem of female Nigerian adolescents. Gender and Behaviour, 12(1), 6113-6124. https://journals.co.za/doi/abs/10.10520/EJC154668

AAUW. (2001). Hostile hallways: bullying, teasing, and sexual harassment in school. Washington: American Association of University Women.

APA. (2007). Task Force on the Sexualization of Girls. (2007). Report of the APA Task Force on the Sexualization of Girls. Retrieved from http://www.apa.org/pi/women/programs/girls/reportfull.pdf 
Angold, A., Costello, E. J., \& Worthman, C. M. (1998). Puberty and depression: the roles of age, pubertal status and pubertal timing. Psychological Medicine, 28 (1),

51-61. https://doi.org/10.1017/S003329179700593X

Bartky, S. L. (1988). Foucault, femininity and the modernization of patriarchal power. In I. Diamond, \& L. Quinby (Eds.), Feminism and Foucault: Reflections on resistance (pp.61-86). Northeastern University Press.

Boursier, V., Gioia, F., \& Griffiths, M. (2020). Objectified Body Consciousness, Body Image Control in Photos and Problematic Social Networking: The Role of Appearance Control Beliefs. Frontiers in Psychology, 11. https://doi.org/10.3389/fpsyg.2020.00147

Butkowski, C. P., Dixon, T. L., \& Weeks, K. (2019). Body surveillance on Instagram: examining the role of selfie feedback investment in young adult women's body image concerns. Sex Roles, 81(5), 385-397. https://doi.org/10.1007/s11199-018-0993-6

Calogero, R. M. (2009). Objectification processes and disordered eating in British women and men. Journal of Health Psychology, 14(3), 394-402. https://doi.org/10.1177/1359105309102192

Calogero, R., \& Jost, J. (2011). Self-Subjugation Among Women: Exposure to Sexist Ideology, SelfObjectification and the Protective Function of the Need to Avoid Closure. Journal of Personality and Social Psychology. 100. 211-28. https://doi.org/10.1037/a0021864

Calogero, R. M., \& Thompson, J. K. (2010). Gender and body image. In Handbook of gender research in psychology (pp. 153-184). Springer, New York, NY. https://link.springer.com/chapter/10.1007/978-14419-1467-5_8

Carver, C. S., \& Scheier, M. F. (1981). Attention and selfregulation: A Control Theory Approach to Human Behavior. Springer Science \& Business Media. https://www.scirp.org/(S(351jmbntvnsjt1aadkposzje ))/reference/ReferencesPapers.aspx?ReferenceID=1 237631

Cash, T. F., \& Smolak, L. (Eds.). (2011). Body image: A handbook of science, practice and prevention. Guilford Press.ISBN-10: 1609181840.

Crawford, M., Lee, I. C., Portnoy, G., Gurung, A., Khati, D., Jha, P., \& Regmi, A. C. (2009). Objectified body consciousness in a developing country: A comparison of mothers and daughters in the US and Nepal. Sex Roles, 60(3), 174-185. https://doi.org/10.1007/s11199-008-9521-4

Cromwell, R. L., Butterfiled, E. C., Brayfield, F. M., \& Curry, J. J. (1977). Acute myocardial infarction: Reaction and recovery. Nursing Research, 26(3), 239. https://doi.org/10.1097/00006199-197705000-00033
Csikszentmihalyi, M., \& Csikzentmihaly, M. (1990). Flow: The psychology of optimal experience (Vol. 1990). New York: Harper \& Row. https://mktgsensei.com/AMAE/Consumer\%20Behavi or/flow_the_psychology_of_optimal_experience.pdf

Dakanalis, A., Carrà, G., Calogero, R., Fida, R., Clerici, M., Zanetti, M. A., \& Riva, G. (2015). The developmental effects of media-ideal internalization and self-objectification processes on adolescents' negative body-feelings, dietary restraint and binge eating. European Child \&Adolescent Psychiatry, 24(8), 997-1010. https://doi.org/10.1007/s00787-014-0649-1

Daniels, E. A., Zurbriggen, E. L., \& Ward, L. M. (2020). Becoming an object: A review of self-objectification in girls. Body Image, 33, 278-299. https://doi.org/10.1016/j.bodyim.2020.02.016.

Dixit, S., Agarwal, G. G., Singh, J. V., Kant, S., \& Singh, N. (2011). A study on consciousness of adolescent girls about their body image. Indian Journal of Community Medicine: official publication of Indian Association of Preventive \& Social Medicine, 36(3), 197. https://doi.org/10.4103/0970-0218.86520

Douvan, E. A. M., Douvan, E., \& Adelson, J. (1966). The adolescent experience. Wiley. https://psycnet.apa.org/record/1974-19904-008

Ernsberger, P., \& Haskew, P. (1987). Health implications of obesity: An alternative view. Journal of obesity and weight regulation (USA).

Herman, S. J. (1994). Engendered Lives: A New Psychology of Women's Experience by Ellyn Kaschak New York: BasicBooks/HarperCollins, 1992, x+ 265 pp. Psychoanalytic Books, 5(4), 561-564. https://www.pepweb.org/document.php?id=pb.005.0561a

Fardouly, J., Diedrichs, P. C., Vartanian, L. R., \& Halliwell, E. (2015). Social comparisons on social media: The impact of Facebook on young women's body image concerns and mood. Body Image, 13, 38-45. https://doi.org/10.1016/j.bodyim.2014.12.002

Festinger, L. (1954). A Theory of Social Comparison Processes. Human Relations, 7(2), 117-140. https://doi.org/10.1177/001872675400700202

Fisher, E., Dunn, M., \& Thompson, J. K. (1998). Social comparison and body image: An investigation of body comparison processes using multidimensional scaling. Journal of Social and Clinical Psychology, 21(5), 566-579.

Fitzsimmons-Craft, E. E., Bardone-Cone, A. M., \& Kelly, K. A. (2011). Objectified body consciousness in relation to recovery from an eating disorder. Eating Behaviors, 12(4), 302-308. https://doi.org/10.1016/j.eatbeh.2011.09.001 
Forbes, G. B., Jobe, R. L., \& Revak, J. A. (2006). Relationships between dissatisfaction with specific body characteristics and the sociocultural attitudes toward appearance questionnaire-3 and objectified body consciousness scale. Body Image, 3(3), 295-300. https://doi.org/10.1016/j.bodyim.2006.07.003

Fredrickson, B. L., \& Roberts, T. A. (1997). Objectification theory: Toward understanding women's lived experiences and mental health risks. Psychology of Women Quarterly, 21(2), 173-206. https://doi.org/10.1111/j.1471-6402.1997.tb00108.x

Fredrickson, B. L., Hendler, L. M., Nilsen, S., O’Barr, J. F., \& Roberts, T. A. (2011). Bringing back the body: A retrospective on the development of objectification theory. Psychology of Women Quarterly, 35(4), 689696. https://doi.org/10.1177/0361684311426690

Frison, E., \& Eggermont, S. (2016). "Harder, better, faster, stronger": negative comparison on Facebook and Adolescents' life satisfaction are reciprocally related. Cyberpsychology, Behavior and Social Networking, 19(3), 158-164. https://doi.org/10.1089/cyber.2015.0296

Garner, D. M., Olmsted, M. P., Bohr, Y., \& Garfinkel, P. E. (1982). The eating attitudes test: Psychometric features and clinical correlates. Psychological medicine, 12(4), 871-878. https://doi.org/10.1017/S0033291700049163

Grabe, S., Hyde, J. S., \& Lindberg, S. M. (2007). Body objectification and depression in adolescents: The role of gender, shame and rumination. Psychology of Women Quarterly, 31(2), 164-175. https://doi.org/10.1111/j.1471-6402.2007.00350.x.

Harter, S., \& Leahy, R. L. (1999). The construction of the self: A developmental perspective. https://eric.ed.gov/?id=ED429699

Hill, M., \& Fischer, A. (2007). Examining Objectification Theory: Lesbian and Heterosexual Women's Experiences with Sexual and Self-Objectification. Counseling Psychologist-Couns Psychol. 36. 745-776. https://doi.org/10.1177/0011000007301669

Hochberg, Z. E., \& Konner, M. (2020). Emerging Adulthood, a Pre-adult Life-History Stage. Frontiers in Endocrinology, 10,918. https://doi.org/10.3389/fendo.2019.00918

John, D. H., \& Ebbeck, V. (2008). Gender-differentiated associations among objectified body consciousness, self-conceptions and physical activity. Sex Roles, 59(9-10), 623-632. https://doi.org/10.1007/s11199. 008-9473-8.

Karsay, K., Knoll, J., \& Matthes, J. (2018). Sexualizing media use and self-objectification: A meta-analysis. Psychology of Women Quarterly, 42(1), 9-28. https://doi.org/10.1177/0361684317743019
Kim, J. W., \& Chock, T. M. (2015). Body image 2.0: Associations between social grooming on Facebook and body image concerns. Computers in Human Behavior, 48, 331-339. https://doi.org/10.1016/j.chb.2015.01.009

Knauss, C., Paxton, S. J., \& Alsaker, F. D. (2008). Body dissatisfaction in adolescent boys and girls: Objectified body consciousness, internalization of the media body ideal and perceived pressure from media. Sex Roles, 59 (9), 633-643. https://doi.org/10.1007/s11199-008-9474-7

Lewis, M. (2008). Self-conscious emotions: Embarrassment, pride, shame and guilt. In M. Lewis, J. M. Haviland-Jones, \& L. F. Barrett (Eds.), Handbook of emotions (p. 742-756). The Guilford Press. https://psycnet.apa.org/record/2008-07784-046

Lindberg, S. M., Hyde, J. S., \& McKinley, N. M. (2006). A measure of objectified body consciousness for preadolescent and adolescent youth. Psychology of Women Quarterly, 30(1), 65-76. https://doi.org/10.1111/j.1471-6402.2006.00263.x

Loughnan, S., Fernandez-Campos, S., Vaes, J., Anjum, G., Aziz, M., Harada, C.,...,\& Tsuchiya, K. (2015). Exploring the role of culture in sexual objectification: A seven nations study. Revue Internationalede Psychologie Sociale, 28(1), 125-152.

Martins, Y., Tiggemann, M., \& Kirkbride, A. (2007). Those speedos become them: The role of selfobjectification in gay and heterosexual men's body image. Personality and Social Psychology Bulletin, 33(5), 634-647. https://doi.org/10.1177/0146167206297403.

McKinley, N. M. (2006). The developmental and cultural contexts of objectified body consciousness: A longitudinal analysis of two cohorts of women. Developmental Psychology, 42, 679-687. https://doi.org/10.1037/0012-1649.42.4.679

McKinley, N. M., \& Hyde, J. S. (1996). The objectified body consciousness scale: Development and validation. Psychology of Women Quarterly, 20(2), 181-215. https://doi.org/10.1111/j.14716402.1996.tb00467.x

Moradi, B. (2010). Addressing gender and cultural diversity in body image: Objectification theory as a framework for integrating theories and grounding research. Sex Roles, 63(1), 138-148. https://doi.org/10.1007/s11199-010-9824-0.

Muehlenkamp, J. J., \& Saris-Baglama, R. N. (2002). Self-objectification and its psychological outcomes for college women. Psychology of Women Quarterly, 26(4), 371-379. https://doi.org/10.1111/14716402.t01-1-00076

Noll, S. M., \& Fredrickson, B. L. (1998). A mediational model linking self-objectification, body shame and disordered eating. Psychology of Women Quarterly, 22(4), 623-636. https://doi.org/10.1111/j.14716402.1998.tb00181.x 
Noser, A., \& Zeigler-Hill, V. (2014). Investing in the ideal: Does objectified body consciousness mediate the association between appearance contingent selfworth and appearance self-esteem in women?. Body image, $11(2)$, $119-125$ https://doi.org/10.1016/j.bodyim.2013.11.006.

Paraskeva, N., Lewis-Smith, H., \& Diedrichs, P. C. (2017). Consumer opinion on social policy approaches to promoting positive body image: Airbrushed media images and disclaimer labels. Journal of Health Psychology, 22(2), 164-175. https://doi.org/10.1177/1359105315597052

Parent, M. C., \& Moradi, B. (2015). Selfobjectification and condom use self-efficacy in women university students. Archives of Sexual Behavior, $44(4)$, 971-981. https://doi.org/10.1007/s10508-014-0384-1

Quinn, D. M., Kallen, R. W., \& Cathey, C. (2006). Body on my mind: The lingering effect of state selfobjectification. Sex Roles, 55(11-12), 869-874. https://doi.org/10.1007/s11199-006-9140-x

Rankin, J. L., Lane, D. J., Gibbons, F. X., \& Gerrard, M. (2004). Adolescent self-consciousness: Longitudinal age changes and gender differences in two cohorts. Journal of Research on Adolescence, 14(1), 1-21. https://doi.org/10.1111/j.15327795.2004.01401001.x

Rodin, J., Silberstein, L., \& Striegel-Moore, R. (1984). Women and weight: a normative discontent. Nebraska Symposium on Motivation. Nebraska Symposium on Motivation, 32, 267-307.

Rosenberg, M. (1965). Society and the adolescent selfimage. Princeton university press. https://www.jstor.org/stable/j.ctt183pjjh

Rubin, L. R., Nemeroff, C. J., \& Russo, N. F. (2004). Exploring feminist women's body consciousness. Psychology of Women Quarterly, 28(1), 27-37. https://doi.org/10.1111/j.1471-6402.2004.00120.x

Schooler, D., Kim, J. L., \& Sorsoli, L. (2006). Setting rules or sitting down: Parental mediation of television consumption and adolescent self-esteem, body image and sexuality. Sexuality Research \& Social Policy, 3(4), 49-62. https://doi.org/10.1525/srsp.2006.3.4.49

Schraer, R. (February 11, 2019). "Is young people's mental health getting worse?". Health. BBC. Retrieved December 26, 2020.

Sinclair, K. R. (2010). Objectified body consciousness, depression and eating disorders: The importance of control beliefs. Yale Review of Undergraduate Research in Psychology, 1, 68-77. https://doi.org/10.1037/e525782013-006

Sinclair, S. L., \& Myers, J. E. (2004). The relationship between objectified body consciousness and wellness in a group of college women. Journal of College Counseling, $\quad 7(2), \quad 150-161$. https://doi.org/10.1002/j.2161-1882.2004.tb00246.x
Slater, A., \& Tiggemann, M. (2010). Body image and disordered eating in adolescent girls and boys: A test of objectification theory. Sex Roles, 63(1-2), 42-49. https://doi.org/10.1007/s11199-010-9794-2

Smith, R. E., Smoll, F. L., \& Schutz, R. W. (1990). Measurement and correlates of sport-specific cognitive and somatic trait anxiety: The Sport Anxiety Scale. Anxiety research, 2(4), 263-280. https://doi.org/10.1080/08917779008248733

Smolak, L., \& Levine, M. P. (2001). Body image in children. In J. K. Thompson \& L. Smolak (Eds.), Body image, eating disorders and obesity in youth: Assessment, prevention and treatment (p. 41-66). American Psychological Association. https://doi.org/10.1037/10404-002

Spitzack, C. (1990). SUNY series in gender and society. Confessing excess: Women and the politics of body reduction. State University of New York Press.

Spitzer, B. L., Henderson, K. A., \&Zivian, M. T. (1999). Gender differences in population versus media body sizes: A comparison over four decades. Sex Roles, 40(7), 545-565. https://doi.org/10.1023/A:1018836029738

Stice, E., \& Whitenton, K. (2002). Risk factors for body dissatisfaction in adolescent girls: A longitudinal investigation. Developmental Psychology, 38(5), 669. https://doi.org/10.1037//0012-1649.38.5.669.

Strauss, J., Sullivan, J. M., Sullivan, C. E., Sullivan, S. J., \& Wittenberg, C. E. (2015). Contextualizing the "Student Body" Is Exposure to Older Students Associated With Body Dissatisfaction in Female Early Adolescents?. Psychology of Women Quarterly, 39(2), 171-181. https://doi.org/10.1177/0361684314550407

Tanner, J. M. (1971). Sequence, tempo and individual variation in the growth and development of boys and girls aged twelve to sixteen. Daedalus, 907-930. https://www.jstor.org/stable/20024040?seq=1

Tantleff-Dunn, S., Thompson, J. K., \& Dunn, M. E. (1995). The feedback on physical appearance scale (FOPAS): Questionnaire development and psychometric evaluation. Eating Disorders, 3(4), 332-341. https://doi.org/10.1080/10640269508250063

Taylor, C. (1989). Sources of the self: The making of the modern identity. Harvard University Press. https://psycnet.apa.org/record/1989-98316-000

Thompson, J. K., Heinberg, L. J., Altabe, M., \& TantleffDunn, S. (1999). Exacting beauty: Theory, assessment and treatment of body image disturbance. American Psychological Association. https://doi.org/10.1037/10312-000

Tiggemann, M. (2013). Objectification theory: Of relevance for eating disorder researchers and clinicians?. Clinical Psychologist, 17(2), 35-45. https://doi.org/10.1111/cp.12010 
Tiggemann, M., \& Williams, E. (2012). The role of selfobjectification in disordered eating, depressed mood and sexual functioning among women: A comprehensive test of objectification theory. Psychology of Women Quarterly, 36(1), 66-75. https://doi.org/10.1177/0361684311420250

Tolaymat, L. D., \& Moradi, B. (2011). US Muslim women and body image: Links among objectification theory constructs and the hijab. Journal of Counseling Psychology, 58(3), 383. https://doi.org/10.1037/a0023461.

Tolman, D. L., Impett, E. A., Tracy, A. J., \& Michael, A. (2006). Looking good, sounding good: Femininity ideology and adolescent girls' mental health. Psychology of Women Quarterly, 30(1), 85-95. https://doi.org/10.1111/j.1471-6402.2006.00265.x

Twenge, J. (October 19, 2017). "Teens are sleeping lessbut there's a surprisingly easy fix". The Conversation.

Tylka, T. L. (2004). The Relation Between Body Dissatisfaction and Eating Disorder Symptomatology: An Analysis of Moderating Variables. Journal of Counseling Psychology, 51(2), 178. https://doi.org/10.1037/0022-0167.51.2.178

Tylka, T. L., \& Hill, M. S. (2004). Objectification theory as it relates to disordered eating among college women. Sex Roles, 51(11-12), 719-730. https://doi.org/10.1007/s11199-004-0721-2
Tylka, T. L., \& Sabik, N. J. (2010). Integrating social comparison theory and self-esteem within objectification theory to predict women's disordered eating. Sex Roles, 63(1-2), 18-31. https://doi.org/10.1007/s11199-010-9785-3

Ussher, J. M. (1989). The psychology of the female body. Taylor \& Frances/Routledge. https://psycnet.apa.org/record/1989-98346-000

Velez, B. L., Campos, I. D., \& Moradi, B. (2015). Relations of sexual objectification and racist discrimination with Latina women's body image and mental health. The Counseling Psychologist, 43(6), 906-935. https://doi.org/10.1177/0011000015591287

Warren, M.P. (1983). Effects of Undernutrition on Reproductive Function in the Human, Endocrine Reviews, 4(4), 363-377, https://doi.org/10.1210/edrv-4-4-363

Weichold, K., Silbereisen, R. K., \& Schmitt-Rodermund, E. (2003). Short-term and long-term consequences of early versus late physical maturation in adolescents. https://doi.org/10.1017/CBO9780511489716.013

Wolf, N. (1991). The Beauty Myth: How Images of Beauty are Being Used Against Women Vintage: London. https://www.jstor.org/stable/20771032?seq=1 